\title{
/LITERATURA/ \\ INVESTIGACIONES SOBRE EL CAMPO ENTRE POESÍA $\mathrm{Y} \ll \mathrm{CÍBER} »$
}

\author{
Miguel ÁNGel GARRIDO GALlaRdo \\ CCHS/CSIC \\ Madrid
}

\section{RESUMEN}

Este trabajo se propone establecer los límites definitorios del término literatura en su sentido estético con las precisiones que se derivan de la historia cultural de sus dos siglos de vida y de la limitación que le impone la irrupción de la cultura cibernética. Propondrá además algunas consecuencias institucionales que implica la noción de literatura a tenor del desarrollo mencionado. Se trata de una investigación que conecta estudios filológicos y estudios culturales, respetando sus respectivos estatutos epistemológicos.

Palabras claves: Teoría literaria, Poética, Retórica, Lexicología literaria, Lexicografía literaria, Terminología literaria, Semántica.

\section{/LITERATURA/ \\ RESEARCH ABOUT THE FIELD BETWEEN POETRY AND «CYBER»}

\section{ABSTRACT}

This paper proposes to establish the definitional boundaries of the term literatura in its aesthetic sense from points that derive from the cultural history of its two centuries of existence and from the limitation imposed on it by the irruption of cyberculture. It will also put forward some of the institutional consequences implied by the notion literatura in accordance with the development of this culture. This research connects philological and cultural studies, respecting their respective epistemological criteria.

Key Words: Literary theory, Poetics, Rhetoric, Literary lexicology, Literary lexicography, Literary terms, Semantics. 


\section{LITERATURA}

La acertada delimitación semántica del término literatura en su sentido estético $^{1}$ es absolutamente imprescindible a la hora de configurar un diccionario de términos literarios (Garrido Gallardo, 2007) y entraña una gran importancia para conocer el campo institucional que cubre y sacar consecuencias al respecto.

Otros antes que yo han intentado estudiar en los últimos años la función y significación que cabe atribuir a la literatura y a los estudios literarios en la cultura del siglo XXI, caracterizada por la comunicación audiovisual, los medios de comunicación de masas y la cibernética (Reiss, 1992; Chico Rico, 2007). Me decido yo ahora a presentar el resultado de mi reflexión, sin dejar de mirar lo que han dicho los colegas, pero ateniéndome a mi propia investigación de los hechos.

Al decir literatura, debo recordar enseguida que literatura, con el perfil que hoy damos por supuesto, en sus variadas acepciones (Escarpit, 1962), es un término que solo tiene una vigencia de dos siglos, el siglo XIX y el $\mathrm{XX}$, pero que todavía no existía como tal en el siglo XVIII y que se está viendo hostigada en sus fronteras en estos comienzos del siglo XXI.

En el siglo XVIII se hablaba de «poesía» con el término aristotélico que significa creación o recreación: «a la recreación hecha con palabras le ocurría, según Aristóteles, que no tenía en su tiempo un nombre particular» ${ }^{2} \mathrm{y}$, así, sin nombre particular fue sobreviviendo siglo a siglo el hecho y la disciplina que lo estudiaba (Poética: «Sobre la creación»).

Litteratura, derivada de litterae (letras, cartas, escritos en general) aparece ya una vez con un sentido compatible con el de los dos últimos siglos en la Institutio oratoriae (II, 4) de Quintiliano (siglo I), pero es por pura casualidad: en determinado contexto, está claro que podemos nombrar una obra de creación como «escrito».

Se da por aceptado, sin embargo, que la primera persona que emplea, de modo más o menos titubeante, literatura en el sentido moderno (o sea en conexión con el antiguo sentido de poesía) es Mme. Stäel en torno a $1800^{3}$. La difusión de la Galaxia Guttenberg (McLuhan, 1964), que había

\footnotetext{
${ }^{1}$ El término español, que es el que tratamos, conserva, junto a su acepción artística, heredera de poesía, la acepción etimológica que se da en expresiones como «literatura médica», «literatura especializada», etc. Algo parecido, aunque no exactamente igual, aparece en las principales lenguas de cultura y, desde luego, en las románicas a las que quizás cabe aplicar cuanto aquí diremos sin hacer diferencias.

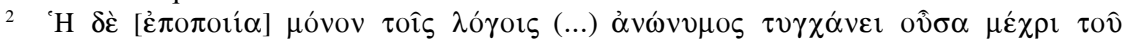
vôv $1447^{\mathrm{a}}$

${ }^{3}$ Es necesario subrayar la importancia de la literatura considerada en su acepción más extendida, o sea, la que engloba los escritos filosóficos y las obras de imaginación, todo lo
} 
propiciado la proliferación del libro y el surgimiento del periodismo, propicia también que nos fijemos en el carácter de escrito que tiene el soporte de toda creación hecha con palabras y que la denominemos así por metonimia. Queda atrás la Historia de la Literatura del P. Andrés (17841806) en la que literatura significaba «escrito» e historia de la literatura algo así como «bibliografía».

Ocurre también otro cambio. Como la creación se había ofrecido desde el principio con frecuencia en moldes rítmicos, que eran señal y justificación de una intención creadora, pero tal exigencia había dejado de ser universal, queda entonces restringido el uso de «poesía» para el molde y no para el contenido: encontramos que la literatura se puede presentar en poesía y prosa. Así la hemos conocido los que abrimos los ojos en el siglo XX (Fumaroli, 1980; Schaeffer, 1983).

Nadie pensará, no obstante, que el hecho humano que está detrás de la literatura es igualmente temporal y perecedero. No. Lo temporal y perecedero es la forma de verlo cristalizado en el lenguaje, pero que haya personas a las que les gusta contar historias o transmitir sentimientos y que haya otras a las que nos gusta que nos cuenten historias o nos transmitan sentimientos es algo que pertenece a lo eterno del ser humano y salta de cultura en cultura: por eso, por ejemplo, podemos emplear sin inmutarnos el oxímoron «literatura oral».

A lo largo del siglo Xx, el desarrollo de los medios audiovisuales ha planteado un radical interrogante a la literatura, que se ha visto incrementado de manera notable a finales de siglo XX y principios del siglo XXI por la revolucionaria incidencia de las nuevas tecnologías.

En septiembre de 2003 dictaba yo un curso en la Universidad de Puerto Rico y vinieron a invitarme a pronunciar una conferencia en un ateneo. «Se trata de un público no especializado, me dijeron. Conviene que aborde un tema general» «¿Puedo hablar de cómo se comenta una novela?» inquirí yo. «Ah, quiere hablar de televisión. Está bien». Para mis interlocutores, el término «novela» sin más explicaciones significaba telenovela y sería, al contrario, la referencia al soporte libro la que estaría necesitada de explicitación.

El cine y la televisión, en efecto, han sustituido muchas veces con ventaja la acción de leer un libro en que se nos cuenta una historia. Los niños de hoy consumen dibujos animados y películas desde su más tierna infancia. Para ellos, la antigua literatura oral de los cuentos narrados por su abuela dista mucho de ser lo único connatural.

que concierne, en fin, al ejercicio del pensamiento en los escritos, excepción hecha de las ciencias físicas [Il est nécessaire de retracer l'importance de la littérature considerée dans son acception la plus étendue, c'est à dire renfermant en elle les écrits philosophiques et les ouvrages d'imgination, tout ce qui concerne en fin l'exercice de la pensée dans les écrits, les sciences physiques exceptées. (p.1). 
¿Nos tendremos que disponer a aceptar la desaparición del libro, de la literatura? Algunos agoreros así lo dicen, pero me parece que no son esas las perspectivas que se presentan (Kernan, 1990; Nunberg comp.,1996). Cuando se empezó a difundir el vídeo doméstico, también hubo quien anunció la desaparición del cine, lo que evidentemente no ha llegado a ocurrir. Es cierto que el número de espectadores ha decrecido de modo notable, pero también lo es que se ha recategorizado el hecho de salir a ver una película. Una cosa es tumbarse en el sofá al final de la jornada y contemplar en duermevela la película que ponen en el televisor y otra es salir a la calle a cumplir una actividad, normalmente integrada en un plan más amplio, en la que nuestra actitud de espectador será más voluntaria y más activa. La incidencia de la tecnología ha diversificado las opciones, pero la del «cine» de antes sigue ahí, minoritaria, pero con más entidad.

Supondría también una refutación a la hipótesis de la desaparición de la literatura su superproducción editorial, sobrevenida al calor del abaratamiento de costes que han propiciado las nuevas tecnologías, a no ser porque también son miles y miles los libros que se publican y no se leen, quedándose relegada su función a la vanidad del autor que paga (Autores auto-financiados, los AAF de Umberto Eco en El Péndulo de Foucault) y a la finalidad del político cuyo apoyo a la cultura es del tipo «superfragilístico espialidoso» (no quiere decir nada, pero es prestigioso). Sin duda, el dato de producción es compatible con una «corriente profunda» que corre en dirección contraria.

\section{CÍBER}

Más allá de esta competencia, la literatura ha visto surgir con ímpetu otro fenómeno textual ciertamente distinto, la textualidad electrónica, el fenómeno «cíber» (Schnell ed., 2009). Como se sabe, hacia mediados del siglo XX, Norbert Wiener estableció en su libro La Cibernética. El control y la comunicación en el animal y la máquina (1948), una serie de conceptos fundamentales que afectan tanto a los sistemas orgánicos como a los inorgánicos, es decir a cualquier sistema que contenga un bucle de retroalimentación de la información. En consecuencia, no se refiere exclusivamente al modo de textualidad electrónica, aunque nosotros adoptemos esta restricción, ya que estamos operando con otra, la de considerar «literatura» (texto literario) en los estrechos márgenes de la referida Galaxia Guttenberg y su consecuencia más contundente, que es el libro.

Pero lo que nos interesa resaltar ahora es que, salvo que consideremos la electrónica como un mecanismo inocuo, que se reduce a lo que hace quien, mientras viaja, lee un libro en su agenda electrónica en la que ha vertido el original escaneado, el lector electrónico propiamente hablando, 
el lector del cibertexto, no es un lector como el lector literario, ni siquiera es un lector. Como dice Aarseth (1997: 1):

\begin{abstract}
El cibertexto coloca a su lector potencial en una posición de riesgo: el riesgo del rechazo. La energía y el esfuerzo exigido al lector por el cibertexto llevan la interpretación hasta el grado de la intervención. Intentar conocer un cibertexto es una inversión de improvisación personal que puede dar como resultado la intimidad o el fracaso. Las tensiones existentes en un cibertexto, aunque no son incompatibles con las del deseo narrativo, son también algo más que éstas: una lucha no solo por la idea interpretativa, sino también por el control narrativo: «quiero que este texto cuente $m i$ historia; la historia que no podría darse sin mí». En algunos casos eso es literalmente cierto; pero, en otros casos, quizás la mayoría, la sensación de resultado individual es ilusoria, pero aun así el aspecto de coerción y manipulación es real.
\end{abstract}

Esto nos lleva al fenómeno que llama Aarseth literatura ergódica (de

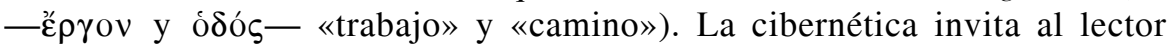
a un trabajo de cooperación y creación que no es necesario (o, al menos, no es igualmente necesario y en el mismo sentido) en las operaciones de lectura literaria. El lector del cibertexto está llamado a ser un jugador, a descubrir caminos inexplorados mediante las estructuras topológicas de la maquinaria textual.

Nos encontramos en el mundo del llamado hipertexto. Hace ya tiempo que Nelson (1987:12.) acuñó este término. El hipertexto es una colección de escritos que un lector puede transitar en el ordenador sin una dirección predeterminada. Cada segmento contiene enlaces que remiten a otros segmentos y éstos, a su vez, a otros, de manera indefinida. En el trayecto, podemos hacer paradas y basta con pinchar en distintos lugares para que aparezca ante nuestros ojos una página concreta. Este tipo de lectura facilita la búsqueda de forma instantánea, pues podemos encontrar en un momento lo que antes nos costaba todo un lapso más o menos largo afanados en trabajosa búsqueda. Se trata en primer lugar de un fabuloso ahorro de tiempo.

Ahora bien, lo que tenemos delante es algo radicalmente diferente de la página impresa que caracteriza al libro y, por consiguiente, la noción de literatura. A lo largo de la linealidad del texto literario aparecen en forma de alusiones (o de notas, en el texto convencional) infinidad de discursos ajenos y entrevistos, pero su presencia es de orden metafórico, absolutamente distinta de la que se obtiene pinchando en el enlace correspondiente del cibertexto. La noción de «cierre» textual que resulta tan característica en literatura (Lázaro Carreter, 1976:32) se torna literalmente imposible, ya que el texto escrito se vuelve el texto escribible (Barthes, 1970:558), o sea, «ese espacio social que no deja ningún lenguaje a salvo, ni a ningún sujeto de enunciación en condición de juez, maestro, analista, confesor, intérprete» (1971:1217). 
El nuevo modo de lectura confluye con la postura filosófica postmoderna. El recorrido informativo no estará ya marcado por las previsiones de un autor, no gozará de ninguna garantía y se convertirá en el libre acceso a los bancos de datos de que hablaba J. F. Lyotard (1979), una inmensa biblioteca que es un tablón de anuncios en que los usuarios pueden establecer conexiones libremente.

Stuart Moulthrop (2003: 29-30) propone tres principios que podrían incorporarse al diseño de los hipertextos del futuro:

1. El hipertexto no es un objeto, sino un sistema. Es ésta una simple reedición de la distinción de Barthes entre la obra y el texto. Los diseñadores de la próxima generación de hipertextos no deberían producir libros de textos para cursos básicos. El hipertexto no es un artefacto que pueda definirse como un volumen impreso: es más bien una colección dinámica y expandible de escritura cuyos contenidos cambian de un día para otro. No se parece en absoluto a un libro y solo parcialmente puede compararse a una biblioteca: es más bien como una universidad, en el sentido de que conjuga el legado más antiguo con las contribuciones más recientes. Y como ningún sistema necesita realmente partes permanentes, es mejor que no dependa en exceso de una estructura básica de textos canónicos o definitivos.

2. El hipertexto es un medio. Todos los proyectos hipertextuales alojan la escritura y la lectura. La función de un sistema hipertextual no es simplemente la de difundir información, sino también la de crear condiciones mejores para el intercambio, desarrollo y valoración de las ideas. Los usuarios del hipertexto académico habrían de ser capaces de explorar los vínculos entre áreas diversas del discurso, pero también de crear vínculos propios entre sus textos y los textos del sistema. Como es un medio público de comunicación, el sistema hipertextual debe estar administrado por un cuerpo representativo: idealmente, por una comisión en la que participen todos los tipos de usuarios (estudiantes, profesores, etc.).

3. El hipertexto tiene que ser variado. Los primeros dos principios suscitaban un problema crucial: ¿cómo puede una institución académica apoyar la libre expresión y, a la vez, mantener estructuras significativas de conocimiento? Si todos pueden cambiar el sistema, y si tanto los profesores como los estudiantes tienen privilegios autoriales, ¿cómo se mantendrán los privilegios imprescindibles? La solución es simple: el sistema hipertextual no necesita ser una matriz uniforme, sino una red heterogénea de espacios textuales. Las mejores propuestas hipertextuales proporcionarán áreas discursivas separadas, que se regirán por convenciones distintas. Un área puede ser una aplicación de la biblioteca y sólo permitirá acceso para la lectura, y mantendrá archivos permanentes. Otras áreas podrían permitir el vínculo y el privilegio de escritura, pero solo para algún tipo de usuario determinado (por ejemplo, estudiantes matriculados en algún tipo de curso), mientras que otras no permitirán la contribución. Pero la división del hipertexto en áreas no debe conducir a su balcanización. Aunque pueda valorarse de forma distinta la relevancia del discurso de cada área, ninguna de ellas debería estar sometida a intervención editorial o censura y todas deberían estar abiertas, al menos para la lectura, a todos los miembros de la comunidad.

La página que acabo de transcribir se refiere de modo particular a la tarea educativa y a la institución académica, pero, sean cuales sean las 
ventajas del hipertexto así concebido, independientemente de la revolución social que pueda entrañar en el diseño del control de la información, lo que está claro es que crea un mundo en que el discurso no está dividido en obras y, por consiguiente, es ajeno al universo de la literatura que se constituye precisamente con el conjunto de obras que tienen (o a las que se les reconoce) una cierta función o virtualidad. Los géneros literarios tradicionales dejan de ser literarios cuando se enfrentan con el nuevo medio, aunque quepa mantener una cierta continuidad de origen, incluso (o sobre todo) en el nombre, como veremos a continuación.

\subsection{Ciberpoesía}

El primer apartado que consideraremos, siguiendo a Joan-Elias Adell (2004), es el de la llamada poesía digital, también conocida como poesía electrónica, poesía informática, e-poesía o ciberspoesía, o sea, la continuidad cibernética del término «poesía» (tomado en el sentido de denominación de género dentro del espacio literario y no como cuasi sinónimo de «literatura»).

Se trata de aquellos poemas realizados mediante un programa de ordenador y que necesitan también del ordenador para ser leídos. La primera impresión que se obtiene es la de encontrarnos ante nuevas técnicas que facilitan poéticas de vanguardias como las que estuvieron de moda en la década de 1950 y que se vinculaban a los experimentalismos de principios del siglo XX (futurismo, dadaísmo, surrealismo).

La poesía electrónica tiene ya una larga tradición que arranca de los experimentos de Théo Lutz en Alemania y Brion Gyon en los Estados Unidos, que consiguieron en 1959, con independencia el uno del otro, programar una «calculadora» capaz de generar los primeros versos libres electrónicos, lo cual engarza con el interés de Raymond Quenau y otros del OULIPO («Ouvroir de Littérature Potentielle») ${ }^{4}$ por crear una producción combinatoria y aleatoria mediante el uso de los ordenadores.

Esta poesía, verdaderamente automática, capaz de producir textos diferentes hasta el infinito, se desvincula radicalmente del origen que el poema tiene en su autor, el poeta, así como del puesto que al lector u oyente cabía otorgarle en el proceso de la comunicación poética. No se trata aquí de calibrar la calidad de los resultados, que ha llevado a algunos a calificar de subliteraria toda la producción electrónica, sino en la transferencia de la instancia creativa que pasa aquí al trabajo de construcción de la

${ }^{4}$ El OULIPO conoce en 1981 una derivación informática, ALAMO (Association pour la Littérature Asistée par la Mathématique et par l'Ordinateur). 
máquina y a la combinatoria posible de las unidades textuales, en la determinación del programa, que es más importante que el texto que pueda resultar. Ciertamente, los vanguardistas ponían la potencialidad del lenguaje por encima del sujeto-autor. Así lo ilustra Adell con una cita de Italo Calvino:

Alguien podrá objetar que cuando más tiende la obra a la multiplicación de los posibles, más se aleja del unicum que es el self de quien escribe, la sinceridad interior, del descubrimiento de la propia verdad. Al contrario, respondo, ¿qué somos, qué es cada uno de nosotros sino una combinatoria de experiencias, de informaciones, de lecturas, de imaginaciones? Cada vida es una enciclopedia, una biblioteca, un muestrario de estilos donde todo se puede mezclar continuamente y reordenar de todas las formas posibles (1988:285).

Para los campeones de la muerte del sujeto, principio y fin de la postmodernidad, la poesía electrónica, la ciberpoesía, es una confirmación del horizonte que habían ya abrazado mucho antes.

No diremos, pues, que la posibilidad que constituye la poesía electrónica no estuviera entrevista, pero sí que no es literatura en el sentido radical. La lectura de un poema generado automáticamente o de un texto de poesía animada visual dinámica es algo totalmente distinto de la experiencia del poema en el formato impreso. Leer es una actividad que rastrea indefectiblemente el sentido (incluso simplemente presunto) otorgado por un autor; en cambio, el sentido radicalmente ambiguo de los textos electrónicos supone una experiencia nueva. Desde luego, la poesía electrónica no es simplemente la poesía que se lee en pantalla, sino la que responde a una poética de la programación, de los códigos, de los algoritmos y de los cálculos. La ciberpoesía no es, insisto, la sustitución de la página impresa por la pantalla, sino la voluntad de entregarse a la transformación que ofrece el ciberespacio. Esta transformación ocurre de un modo especial en lo que se empezó a llamar en los años 80 «poesía animada» donde lo visto y leído en la pantalla cobra vida y se apropia del espacio exterior. Se trata de un «salto» que aparece traspasando el límite de la poesía literaria que quisiera entregar el objeto único, aunque no puede porque lo que entrega es un mensaje vinculado a un código, el cual, si es verdaderamente código, no puede ser único y si es verdaderamente único, no puede ser compartido, no puede ser código.

La naturaleza intersemiótica de la poesía electrónica (lengua natural, artes plásticas, música, cine) pone claramente de relieve que el salto se ha experimentado, aunque en una dirección ya establecida: como venimos diciendo, la dirección marcada por la poesía de vanguardia o experimental. Según recuerda Fernando Cabo (2001: 87), Gadamer advertía que una de las características de la poesía contemporánea era la de producir palabras aisladas, desagregadas de sus conexiones lógicas, de modo que su 
propio aislamiento potencia su dimensión virtual. Adviene una nueva dimensión temporal y topográfica, que no tiene nada que ver con el tratamiento del tiempo y el espacio en la narración literaria, por ejemplo, sino con el hecho de que no se cuenta con un texto presente de principio a fin como ocurre con el libro o con la película de cine. El texto se gesta en nuestra presencia y es preciso contar, como dice Joan-Elies Adell (2004:295) con «la dimensión temporal, la dimensión espacial o topográfica (las coordenadas que transitan por una superficie) y la dimensión del movimiento, cinética».

El trabajo de Joan-Elies Adell que venimos parafraseando hace finalmente referencia a la experiencia de los «poemas de lectura única», o sea, poemas que serán confeccionados una sola vez y que, después de leídos, se borrarán sin posibilidad de ser rastreados. Passage de Philippe Bootz se organiza, según explica el autor, en tres fases: la primera, de textos multimedia que introducen el componente narrativo del texto; la segunda, interactiva, en la que el lector puede escoger entre la lectura siguiente y la lectura del prólogo y está formada por un hipertexto en que cada nodo puede ser activado una sola vez; la tercera, es un generador automático de texto animado que solamente genera un único texto: la respuesta al estado de petición resultante de la interactividad de la fase precedente. El texto animado final contiene una historia para quien la ha «escrito», pero excluye cualquier otro lector posible.

\subsection{Narración hipertextual}

Jürgen Fauth (2003) compara la narración hipertextual que ha posibilitado la cibernética con la narrativa literaria («plana») y obtiene una serie de conclusiones del mayor interés para nuestro propósito de delimitación. Conceptúa el nuevo producto de calidad inferior por cuanto propende a la dimensión lúdica superficial, ya que los autores se ven tentados de usar y abusar de los nuevos efectismos posibles, aunque ciertamente, esto puede ser defecto de principiantes y quedar superado con el afianzamiento de la práctica.

Pero a lo que vamos es a precisar la naturaleza específica de la hipernarración (frente a la narración literaria) y eso, incluso si se trata de la modalidad explorativa u obra de solo el autor, y no de la constructiva, aquella en la que el lector está invitado a añadir o suprimir partes de la historia.

No hay duda de que la diferencia existe, pero hay que precisarla. Me parece que la dicha diferencia es menor de lo que tienden a subrayar los que se dan cuenta de que estamos ante un nuevo paradigma y mayor de lo que advierten quienes creen encontrarse ante un simple avatar más de ese 
hecho constante del que venimos hablando que «está detrás» del fenómeno literario.

A estas alturas, todos estamos convencidos de la importancia del lector en la comunicación literaria. El lector se recrea en unos pasajes de su lectura y se apresura en otros, lee no solamente lo que el autor «puso», sino lo que su propia cabeza lectora, con su enciclopedia y presuposiciones, le dicta. Toda lectura es individual y crea un espacio tridimensional en que los signos se hace ecos unos de otros, se relacionan en el cotexto y en el contexto, cuentan con el pasado y se proyectan al futuro. Por eso, nos sigue diciendo Fauth, aunque la lectura implícita del hipertexto sea «multilineal», «anti-jerárquica», «centrífuga», «sin principio ni fin evidente» sin «arriba» ni «abajo», los textos lineales finalmente resultantes no son tan diferentes de los textos «planos», la diferencia no es tanta como cupiera pensarse a primera vista.

Sin embargo, la estructura hipertextual presenta rasgos propios, el más significativo de los cuales es el enlace: palabra, frase o icono que envía a un nodo o fragmento del texto y que, a su vez, ofrece más enlaces al incesante movimiento del ratón que el lector puede llevar a cabo. Dice Fauth que la cadena significativa a que da lugar es muy parecida a aquella, característica de la nueva cultura, a la que tanto temía Baudrillard (1981:10) por su carácter mareante y sin sentido.

El enlace hipertextual empezó ofreciendo al lector la posibilidad de elegir entre dos nodos, el lector realizará recorridos diferentes según los nodos que elija y se convertirá, a veces, en un agente perplejo que no sabe cuál sería la mejor elección. Eligiendo, el lector electrónico no solamente llega al último extremo de la posibilidad de cooperación que abrió Rayuela y otros exponentes de la novela más o menos experimental, sino que produce un salto cualitativo. El lector interactivo puede obedecer o discrepar, ampliar o reducir el texto, reorganizarlo, revisarlo, añadirle comentarios. Las fronteras entre autor y lector y entre lector y crítico tienden a desaparecer en estos especímenes. La nueva realidad se parece más a la poesía oral del aedo o rapsoda, que sufría las reacciones de su público; incluso se parece más al teatro, que tiene como esencia esa influencia inmediata de la reacción del receptor, a diferencia de la literatura cuyo carácter escritural la mantiene indefectiblemente inalterada (abierta a las diferentes lecturas, pero inalterada).

Ahora bien, el problema se traslada del autor al lector. ¿Cómo saber si se acierta al elegir? ¿En virtud de qué se puede estar seguro de que el comentario no desvirtúa el texto inicial? El lector literario acertará o no en su lectura, pero puede despreocuparse porque ella no influye en nada ni en nadie a continuación. El lector cibernético está obligado a la cooperación.

Hay que tener en cuenta, sin embargo, que la cooperación que se da en la narración cibernética no es la que existe entre dos artistas que cola- 
boran, sino entre el diseñador de un juego y el jugador. Fauth nos lo recuerda de la mano de Bolter (1991:130):

Por eso, la literatura electrónica, como la programación informática, seguirá siendo un juego. En los videojuegos de naves espaciales y de robots implacables, el jugador compite contra el programador, quien ha determinado las metas y ha colocado los obstáculos en el camino del jugador. Independientemente de lo competitivo que sea, la experiencia de leer en el medio electrónico sigue siendo un juego, más que un combate, en el sentido de que no tiene conclusión definitiva. El lector puede ganar un día y perder el siguiente. La no permanencia de la literatura electrónica puede interpretarse de las dos maneras: que no hay victoria duradera, pero que tampoco lo es la derrota. La página impresa, por el contrario, incluso en la comedia, en las novelas de amor y en la sátira, se caracteriza por su solemnidad, la cual se sigue de su carácter inmutable.

La propensión al carácter lúdico es consustancial con el hipertexto, pero lo que de verdad lo caracteriza es su referencia al enlace, su obligatoria metaestructura, algo que es ajeno al texto literario o texto «plano», siguiendo la nueva terminología al uso. Así, la narración literaria es necesariamente distinta de la hipertextual. Adoptar y adaptar el modelo hipertextual en el literario solo acarrearía problemas y ninguna ventaja. La narración literaria debe ser vigorosa y continua al contrario que la narración hipertextual en la que el autor renuncia al orden y selección del texto. Además, por mucho que el autor literario quisiera configurar su narración a imitación del modelo hipertextual, no parece que pudiera conseguirlo. Tampoco ganaría nada un relato hipertextual que pretendiera diferenciarse lo menos posible del literario: en el extremo, consistiría tan solo en un texto literario para leer en pantalla, perdiendo entonces, por definición, su condición.

En consecuencia, como la imaginación es cosa de la narración literaria al igual que de la hipertextual, Fauth no le ve a esta segunda otra ventaja que las oportunidades que ofrece para la interacción lúdica. Y pone el ejemplo del cine en 3D que fabricaba películas en las que, a la menor ocasión, se arrojaban objetos contra el espectador para que éste viviese el efecto de tres dimensiones que había acudido a experimentar, sin embargo,

una vez que el director de la película ha entendido que la gran cantidad de objetos esgrimidos contra la cámara y contra los futuros espectadores no mejorará las cualidades narrativas de la película, tendrá que recurrir a los recursos cinematográficos clásicos y usarlos, abusar de ellos, o relacionarse con ellos de modo productivo. Pero, en este caso, ya no serían necesarias esas gafas de papel con un cristal rojo y otro verde para disfrutar de la película (Fauth, 2003: 128).

Insisto en que, con todo, la cuestión no estriba en que la narración hipertextual sea narrativamente (estéticamente) más pobre que la narración literaria, ni siquiera en el debate de si eso es así por sus caracteres intrínsecos o por la falta de práctica en la nueva estrategia en la que «tirar objetos al espectador» es consecuencia de la novedad y no exigencia del propio 
discurso. Aunque la narración hipertextual llegara a conseguir construcciones de una excelente calidad estética, no son pertinentes las comparaciones artísticas como si se tratara del presente y pasado de lo mismo. Lo que aquí se ha mostrado es que narración literaria y narración hipertextual no son dos géneros de un continuum discursivo que sufre una inflexión por la incidencia de las nuevas tecnologías, sino que la narración «plana» es un género literario y la narración cibernética es sencillamente otra cosa.

\subsection{El ciberteatro}

La clasificación de los grandes géneros en épicos, líricos y dramáticos tiene una sólida tradición cultural. Sin embargo, cuando está en juego la delimitación rigurosa del término literatura, hay que recordar que el teatro no es literatura, aunque el texto dramático del que puede partir o al que finalmente llega, pueda ser considerado un género literario más, el dominado por el diálogo y condicionado por la presuposición de una representación, prevista o pasada. Visto solo así, la consecuencia del reto cibernético es el hiperdrama. Como explica Gonzalo Pontón (2003), «obra teatral escrita en hipertexto en la que se sustituye el desarrollo lineal por la simultaneidad, pues se convierte en materia representada aquello que en el teatro convencional no llega a elevarse a la escena: la vida de los personajes durante la ausencia de las tablas» (p. 150). Naturalmente, hay que calificar esta práctica de no literaria, por las mismas razones que venimos viendo, y ajena a lo teatral por las que veremos a continuación.

José Luis García Barrientos (2007) estudia el desafío que para el teatro supone la galaxia cibernética a partir de la doble dicotomía con la que ha caracterizado en su obra dramatológica las condiciones de producción de significado que describen el hecho teatral, la oposición escritura/actuación y la oposición narración/actuación.

La «actuación» opuesta a la «escritura» que caracteriza el teatro lo hace diferir de la literatura, pero también del cine. La comunicación de la «escritura» se realiza en dos fases con solución de continuidad: la producción (autor- obra) y el consumo (obra-espectador), la comunicación de las actuaciones se realiza en una sola fase (actor-público) sin que sea posible separar producción y consumo, creación y recepción.

El autor de la escritura deja un texto completo y definitivo que espera acogida, pero no reacción; el actor es sujeto de una experiencia intersubjetiva, compartida por actores y público que, en cuanto tal experiencia, carece propiamente de autor. García Barrientos ofrece un ejemplo clarificador: un actor o un torero difícilmente podrán acusar de plagio a quienes los imiten, la propiedad intelectual es cosa de autor: «en el cine y las escrituras el sujeto (autor «ausente») desaparece en beneficio del objeto (obra), 
mientras que en el teatro y las actuaciones es la obra (el objeto) la que desaparece en la relación subjetiva (entre actores y espectadores)» (p. 15).

Según lo dicho, la definición del teatro como actuación se fundamenta en la presencia y el presente (Gouhier, 1943: 21), o sea, la concurrencia de dos clases de sujetos, actores y espectadores en un espacio compartido y durante un tiempo también compartido. Pues bien, el ciberespacio, al disociar las coordenadas de espacio y tiempo, hace que no necesariamente se correspondan presencia y presente. El presente comunicativo no presupone ya sin más la presencia de los comunicantes, pues la tecnología permite dicha comunicación sin que sea necesario un contacto en el espacio real.

$\mathrm{Si}$ el teatro exige la presencia en presente, ¿será teatro el ciberteatro porque la interacción en ausencia pueda considerarse una suerte de nueva presencia? ¿Podría seguir llamándose teatro al que solamente ofrece una presencia virtual en un presente real? ¿Debe el teatro darse en vivo y en directo o basta con lo último? García Barrientos plantea estos interrogantes y se muestra escéptico con la posibilidad interactiva de que se dispone, la cual le parece «muy limitada»y, sobre todo, «muy pautada». Quizás es demasiada su aprensión cuando todavía se pregunta si, incluso a los efectos que nos ocupan, en el ciberespacio se da una presencia real como la del teatro o, más bien, la pseudopresencia propia del cine y la televisión.

La oposición narración/actuación cuenta con el abolengo de ser una distinción de Aristóteles, quien en su Poética conceptúa el teatro como uno de los dos modos de creación: narrando lo imitado, «o bien presentando a todos los imitados como operantes y actuantes» $\left(1448^{\mathrm{a}}, 19-24\right)$. Esta distinción modal diferencia claramente teatro y literatura, pero también, aunque pudiera sorprender a primera vista, teatro y cine, pues éste comparte con la narración literaria su carácter mediado: la voz del narrador y el ojo de la cámara son instancias mediadora entre el mundo de ficción y el narrador, que solamente a través de ellos tiene acceso al mundo representado.

Cabe preguntarse ahora si la transmisión en directo que permite la galaxia cibernética nos lleva a admitir que el ciberteatro presenta los correspondientes rasgos teatrales y no es más que una forma de continuidad. García Barrientos responde así:

Entonces, la transmisión en directo, que es de lo que se trata, sea o no interactiva, ¿es actuación por darse en el presente que comparten, segundo a segundo, actores y espectadores? La respuesta parece ahora clara: no, porque el rasgo pertinente no es el tiempo sino la mediación. Y en el directo hay tanta mediación como en el diferido. Lo decisivo es que yo asista a algo viéndolo con mis propios ojos o bien a través de los ojos de la cámara, que son los ojos de alguien que no soy yo, de otro (que, eso sí, solicita o mejor, exige que los míos se identifiquen con los suyos). Creo con Walter Benjamin (1936:48) que 'la naturaleza que habla a la cámara no es la misma que habla al ojo'. Y en la videoconferencia, en el ciberespacio no hay — de momento- ojos, sino cámaras, puntos de vista. (2007: 19-20). 
El crítico no puede estar seguro de que el progreso de las nuevas tecnologías pueda salvar las barreras («insalvables») que hasta ahora nos llevarían a considerar que el ciberteatro no es teatro. Este progreso tendría que proporcionar al espectador «una libertad de mirada» igual o similar a la del ojo humano, a pesar de que lo que mire sean imágenes captadas por una o más cámaras; y, además, un tipo de contacto comunicativo en el ciberespacio entre los espectadores y los actores/personajes semejante al que se produce cuando se encuentran en un espacio real. Sería una relación entre unos y otros de los que componen el público, entre unos y otros de los actores personajes y de los actores con el público y viceversa. El modelo propuesto por la Fura del Baus denominado Work in progress en que los espectadores que forman el público están reunidos en diferentes lugares, realmente presentes y en contacto, en cada sitio, entre ellos facilita más la posibilidad de entrever un auténtico ciberteatro, aunque lejos de la consecuencia última que sería aquella que contemplara la experiencia teatral de cada usuario situado ante su pantalla.

Recapitulemos. Está claro que la ciberliteratura no es literatura. Lo que se conoce como tal o no es cíber, porque se trata solo de la utilización ocasional de un soporte electrónico que sustituye el soporte del libro impreso de la literatura convencional; o no es literatura porque responde a una actividad hipertextual que difiere esencialmente de la actividad que supone la comunicación literaria.

El teatro no es literatura (porque es escritura). El ciberteatro, hoy por hoy, tampoco es teatro, porque no es propiamente actuación. Pero si un día llegara el ciberteatro a ser una especie del teatro, como el teatro no es literatura, nunca llegaría a ser literatura. Por definición.

\section{COMUNICACIÓN}

Quedándonos ya con la noción de literatura de ahora (que ha integrado y recategorizado, con el libro como soporte, la noción de poesía en cuanto sinónimo de creación) no cabe duda de su vigencia y su prestigio cuando la galaxia cibernética se adhiere a su nombre (ciberliteratura) para denominar el nuevo fenómeno y al nombre de sus antiguos géneros en las denominaciones de los suyos como ciberpoesía, hipernarración e hiperdrama.

$\mathrm{Y}$, aunque haya ocasiones de comunicación literaria stricto sensu en que la pantalla no es más que un soporte sustitutorio del libro, lo que yo quiero recordar ahora es que no es lo mismo ponerse ante la pantalla para, por ejemplo, contabilizar el número de oraciones concesivas que aparecen en un poema de Bécquer, que llegar por la noche a casa y, a pesar de los requerimientos de la telebasura, acercarse a la biblioteca, tomar una edición bellamente encuadernada del Libro de los Gorriones y ponerse a leer 
para entretenerse, emocionarse o enriquecerse. Probablemente, además, para la primera acción, acudamos siempre al ordenador —es más cómodo-; para la segunda, acudiremos quizás siempre al libro.

Y he aquí que, dándose el fenómeno humano que está detrás de la literatura en un hecho de comunicación (Corti, 1980; Garrido Gallardo, 2006), la literariedad no dependerá solo del texto ni de la intención que en el texto puso su autor, sino también del lector, el soporte y la ocasión. En el extremo, cuando lo que tomemos por la noche para distraernos sea un recetario de Arguiñano donde encontramos la receta del bacalao al pilpil, la comunicación que establecemos es más «literaria» (lúdica, creativa, si se quiere) que la que habíamos instaurado en la búsqueda de oraciones concesivas del texto de Gustavo Adolfo. Tendría gracia definir la literatura como el texto que no se lee en Internet.

La nueva cultura perfila una nueva literatura en que los libros, tal vez de ediciones cuidadas y bellamente encuadernadas, que tengamos en casa, serán menos (tendremos todos a nuestra disposición en Internet), pero serán selectos $\mathrm{y}$, como digo, posiblemente participarán de un cierto carácter suntuario como las joyas. No tendría nada de extraño que la pretendida crisis del libro conduzca en realidad a una nueva bibliofilia.

La verdad que encierra el comentario que acabo de hacer acerca del recetario de cocina ha conducido, sin embargo, a algunos a un inmenso error: puesto que podemos utilizar El Quijote no literariamente y las $R e$ cetas de Arguiñano como literatura, lo mismo da un texto que otro, ambos serán igualmente objeto de los «Estudios Culturales» encargados de ilustrarlos académicamente.

Huyamos de tan funesta manía contra la que Harold Bloom (1994) se ha convertido casi en vox clamantis in deserto. Una cosa es que la literatura pueda ser recibida no literariamente o que otro texto no literario (por ejemplo, periodístico) pueda ser utilizado como literatura y otra que no exista diferencia entre uno y otro. También existe diferencia entre la alta literatura y la subliteratura, aunque entre una y otra haya una línea continua sin solución de continuidad. Y esto es de siempre. No es ningún dislate pensar que los libros de caballería, leídos por una dama en voz alta mientras las demás (analfabetas) bordaban en sus respectivos bastidores, son rigurosamente paralelos al fenómeno de la telenovela que acabo de evocar. Hay también obras subliterarias de autores literarios. Recordaba yo hace más de treinta años en mi Introducción a la Teoría de la Literatura que la producción de esa figura incomparable de nuestro canon, que es Lope de Vega, pasando historias, más de ciento en horas veinticuatro de las musas al teatro, está llena de obras subliterarias desde cualquier punto de caracterización.

Volviendo a nuestro hilo conductor, no debemos confundirnos, pero tampoco podemos prescindir de los hechos. Los que tenemos que enseñar 
literatura debemos tener en cuenta que nuestro alumnos no han crecido en una sociedad lectora, que sus primeros contactos con las narraciones han sido más a través del vídeo que de los cuentos de la abuela, que los medios audiovisuales, con su inmediatez y facilidad, se ofrecen como alternativa a la actividad de leer.

Y, sobre todo, insisto, la nueva situación nos invita a tener definitivamente en cuenta que el fenómeno que denominamos literatura no se basa en el objeto físico del libro, sino en la modalidad del proceso de comunicación que el libro favorece.

En la década de 1960, se extendió como una mancha de aceite por el mundo académico la convicción de que enseñar literatura consistía en poner en contacto a los alumnos con textos literarios: ¡nada de listas de autores y obras, obliguemos a leer literatura! Se suponía que, producida la lectura, nacería la afición y, erre que erre, para controlar que el alumno leyera La Celestina y no simplemente copiara la ficha de un compañero, se le preguntaba... ipor el grado de parentesco de Pleberio! ¡Pero $\mathrm{LaCe}$ lestina, leída así no es literatura! Lejos de haber logrado que el futuro ingeniero, abogado o economista tuviera una experiencia literaria, se les había inducido a la confusión de que «aquello» era leer literatura y, así, se conseguía que aquellas personas juraran odio eterno a los textos literarios. No solo no habían tenido una experiencia literaria, sino que se les había vacunado contra la posibilidad de que la tuvieran alguna vez. Y así seguimos.

Los filólogos tenemos que abrirnos al discernimiento de todos los procesos comunicativos que sustituyen o compiten con la literatura en el sentido en que la hemos entendido los dos siglos pasados. Muchas veces existen relaciones de realimentación y un libro se hace película por su éxito o se difunde, al contrario, por la película en que se vertió. Lo que hemos dicho de la difícil lectura literaria en el ordenador conoce el contraejemplo de las suscripciones para leer en pantalla novelas de Stephen King. Pero no todo vale igual. Ayudar a discernir el trigo de la paja es una función a la que no podemos (debemos) renunciar.

\section{LA FRONTERA DEL PERIODISMO}

En su época propia, la literatura hace frontera con el periódico. El del periodismo es otro discurso que se desarrolla también a partir del siglo XVIII. Visto, desde hoy, es fundamentalmente el género discursivo de las noticias, pero yo querría más bien fijarme en su dimensión de comentario, dimensión retórica por excelencia en cuanto vehículo de las instancias persuasivas de nuestra sociedad, la cual no se limita por cierto al periodismo escrito. Como sostuve en mi libro La Musa de la Retórica (Garrido Ga- 
llardo, 1994: 183-197), estamos en un era que se caracteriza por una preponderancia de la retórica, absolutamente nueva en la historia (Albaladejo, Chico Rico y Del Río eds., 1998).

Ciertamente el ser humano es retórico por naturaleza y para convencer al interlocutor de su punto de vista echa mano de todos los recursos naturales de los que está dotada su capacidad comunicativa. Eso es permanente. Lo que es nuevo es el dominio de las relaciones mediadas. Antiguamente, el interlocutor era conocido; pertenecía de algún modo a nuestra comunidad; actualmente, tenemos la impresión de inmediatez para quien vemos en televisión hablando en el otro extremo del mundo, pero esa inmediatez, como hemos recordado ya a otro propósito, es engañosa y los datos que obtenemos de ella están casi siempre trucados. El montaje, el punto de vista de la cámara, su encuadre, el parlamento prefabricado que profiere el personaje público pueden no tener nada que ver con la realidad de la situación. Y lo malo es que no hay forma de comprobarlo, que ni siquiera advertimos indicios para fundar una sospecha, incluso por justificada que esté en la realidad.

La violencia que puede generar esta nueva situación de las relaciones mediadas es de un calibre como nunca ha existido, insisto, en la historia de la cultura humana. El maquillaje, las mezclas de sonido y los altavoces, más las noticias construidas sobre falsos escándalos que resultan seductores a sus secuaces, podrán mantener al ídolo de la canción dando vueltas al mundo y triunfando en las listas de ventas, aunque la voz, cascada por los años, y las arrugas, profundizadas por los excesos de una vida de crápula, estén pidiendo a gritos una retirada de escena por el bien de todos.

Esta retórica se ve fomentada por la cultura sofística, que llamamos postmoderna. Si no hay posibilidad de conocer algún tipo de verdad, lo importante no es la capacidad de mostrarla a otros, sino la eficacia en convencer a otros con independencia de cuál sea la «verdad» que, para ese momento, deba ser sacada del armario de los disfraces en el tinglado de la nueva farsa. Es la que he llamado cultura del «homo rhetoricus», que explica además por qué, como antes dije, el Quijote de Cervantes y las recetas de Arguiñano se pueden confundir en nuestro mundo con facilidad. A Aristóteles esto le parecía inmoral ¡Peor para Aristóteles!

No cabe duda, me parece, de que el género periodístico o los géneros del periodismo, por ser más exactos, junto con la publicidad, por supuesto, son los discursos retóricos de la actualidad por encima de la retórica centrada antaño tan solo en la práctica (naturalmente, aún subsistente) de la oratio, de la pieza oratoria inmediata dirigida a un público en una asamblea, en un parlamento, en un tribunal o en un púlpito.

He repetido muchas veces que la retórica funciona en dos pasos fundamentales: llamar la atención y conseguir la adhesión. Son dos pasos suce- 
sivos, porque si no se logra el primero, es imposible alcanzar el segundo. Para el primero, la tradición ha inventariado una notable suma de procedimientos que son las llamadas, grosso modo, figuras retóricas; en el segundo, está todo el campo de la argumentación. Pero no debemos pensar en compartimentos estancos. No hay acción argumentativa más profunda que la de la metáfora, fenómeno que de ninguna manera agota su condición en ser un adorno atractivo, sino que supone una revolución epistemológica, una reestructuración del mundo (Ricoeur, 1975).

Tampoco nos debemos limitar a fijarnos en palabras. La lengua natural o idioma es el núcleo mismo de nuestro despliegue comunicativo, pero hace mucho que la Semiótica puso de relieve hasta qué punto los procedimientos que ponemos en ejecución en el idioma están presentes también en otros códigos.

Pero volvamos a nuestro hilo, aunque tan largo excurso no sea ajeno a la noción de literatura y sus consecuencias, ya que los discursos del periodismo cubren la afición de contar cosas y de recibir lo que nos cuentan que, según he dicho al principio, constituye lo básico de lo que está detrás.

\section{LA RETÓRICA COMÚN}

En diversas ocasiones he puesto de relieve el carácter ambivalente de ciertas realizaciones actuales de géneros periodísticos, que están a caballo entre literatura y periodismo. Ocurre, sobre todo, a partir del llamado «nuevo periodismo» (Wolfe, T., 1975) del siglo XX, pero con antecedentes tan ilustres en nuestra historia como el de Mariano José de Larra, por ejemplo. No voy a insistir en esa cuestión. Quiero centrarme en algo más general, a saber, en el hecho de que el periodismo y la literatura tienen un territorio fronterizo común, que es la Retórica.

Ya he dicho que, excepción hecha de sus contenidos noticiosos en sentido estricto, el periodismo es el campo discursivo donde se vive el combate retórico de la actualidad. He de recordar ahora que toda literatura es retórica en un doble sentido.

Lo es, porque los procedimientos para llamar la atención que pone en práctica el discurso retórico con una finalidad persuasiva deberán ser, al menos en parte, los mismos que articula la literatura con una finalidad estética. He ahí el territorio común. Por lo demás, lo recordaba ya Aristóteles en su poética según he evocado en mi Nueva Introducción a la Teoría de la Literatura (2000: 191-223).

Pero, sobre todo, lo es, porque apenas existe literatura inocente. Todo autor implica en su texto un descubrimiento, un compromiso al que quiere conducir al lector. Solo casos extremos en que la literatura se confunde con la música se podrían presentar como un contraejemplo, pero, en todo 
caso, serán la excepción, si no son más bien deliberados grados cero con los que se quiere atraer, retóricamente, a una percepción del sinsentido o la sinrazón. O sea, si no toda retórica es literatura, toda literatura es retórica y, como la retórica se concreta en gran medida en el periodismo, éste y la literatura tienen también un nervio en común: de ahí también se deduce lo fácil que resulta el nacimiento de géneros híbridos como los que acabo de mencionar y dejar de lado hace un momento y, desde luego, la necesidad de integrar el discurso del periodismo entre los que componen el objeto de esa ampliación de los estudios filológicos que debe ser, bien entendido, el «estudio cultural».

Llegamos a un corolario necesario. La literatura es una encrucijada semiótica riquísima, donde se imbrican lo artístico, lo retórico y lo cultural. Supone exprimir hasta las últimas consecuencias las potencialidades del lenguaje. Exige, por su naturaleza de «libro» (o similar) una actitud activa, una presuposición de vigilia, un plus de atención.

El periodismo es la correa de transmisión de lo ideológico, la retórica que no se da ese nombre, la acción social donde se puede producir por parte del emisor, intencionadamente o no, el ejercicio cotidiano de la violencia.

La retórica es un hecho espontáneo del que no se puede prescindir y, por lo tanto, hay que entrenarse en ella no para adquirir, activamente, un instrumento con el que violentar, sino, pasivamente, un procedimiento de discernimiento, de evitar la violencia. Aunque no sea fácil guiar hasta ella, he aquí por donde, el ejercicio activo que supone la lectura literaria, que implica valorar en todos los aspectos, suma entre sus ventajas de actualidad servir de entrenamiento para ejercer la libertad.

\section{6. ¿QUÉ PASA CON LA TEORÍA?}

En estos tiempos posteriores a la época literaria, los Estudios (de la Literatura) deberán atender su continuación y sus alternativas con naturalidad (Herbrechter and Callus, eds., 2004; García Barrientos, 2006). A nadie extrañará que la película Bienvenido Mr. Marshall, de Berlanga, se estudie en la clase de literatura española de postguerra. La confusión entre Cervantes y Arguiñano no se deriva principalmente de la extrapolación indebida de estos hechos, sino, más bien, de la consecuencia, también indebida, de una posición doctrinal.

Porque mientras iban ocurriendo las cosas relatadas en torno a la noción de literatura, el estructuralismo, que dominaba el panorama universal en la década de 1960, iba siendo sustituido por una pléyade de indagaciones «postestructuralistas» que ponen de relieve el evidente exceso de detenerse en la articulación del enunciado sin parar mientes en que éste no es más que el resultado registrable de un proceso de enunciación, que le otorga 
sentido y, por eso, las claves del proceso son también imprescindibles para su desciframiento. Con todo, el término postestructuralista señala claramente la importancia de este abordaje - el estructuralismo- en el siglo XX, hasta el punto de que todo lo que se hace en «Teoría», dicho sea con toda flexibilidad, se pueda configurar como un «antes» y un «después»: «preestructuralista» o «post-estructuralista».

$\mathrm{Y}$ en este «después» desempeña un papel importantísimo la Desconstrucción como ejemplo relevante de la episteme que subyace en todo pensamiento postmoderno. El estructuralismo filosófico tenía ya una gran carga antimetafísica, de neopositivismo lógico, pero no todo estructuralismo es así. Podemos decir que no todo postestructuralismo es desconstrucción y postmodernismo, aunque, evidentemente, todo postmodernismo y desconstrucción sea postestructuralista. Igualmente, toda desconstrucción es postmoderna, aunque no todo en la postmodernidad sea desconstrucción.

La Desconstrucción (tengo la manía de emplear el prefijo des- y no $d e-$ porque en español es el más frecuente, aunque se diga igualmente, por ejemplo descomponer y depilar) no es propiamente un camino crítico, sino un gran alegato contra la interpretación. En mi necrología de Derrida tuve ocasión de comentarlo. Como sabemos, para Derrida, aceptar que, a pesar de los pesares, de todos los malentendidos, los seres humanos podemos comprender lo que nos dicen los otros en su propio sentido y nos podemos hacer comprender de la misma manera sería un «prejuicio teológico», pues supone el optimismo de pensar que existe la garantía de Dios, única que no pueden admitir quienes, como él, se insertan en la corriente del llamado pensamiento moderno, que se resume en la conocida referencia de Woody Allen: «Dios ha muerto, el hombre ha muerto y yo mismo no me encuentro nada bien». La Desconstrucción postula, pues, que todo texto remite a otro y éste a otro en una serie indefinida. Lo que esto tiene de cierto está obligando a repensar infinitas aseveraciones superficiales. Sin embargo, a partir de 1970, su difusión masiva y mucha veces degradada, sobre todo en los Estados Unidos, ha inducido a que numerosos scholars creyeran encontrar una patente de corso en la Desconstrucción y, en su nombre, interpretaran y reinterpretaran cualquier texto sin discernimiento alguno. Umberto Eco tomaba un tanto a broma tamaños dislates en su obra Los límites de la interpretación (1990). Cuenta que Derrida le había escrito en 1984 una misiva comunicándole que estaba creando con unos amigos un Collège Internationale de Philosophie y pidiéndole una carta de adhesión. «Apuesto que Derrida asumía que

- yo debía asumir que él decía la verdad;

- que yo debía leer su programa como un mensaje unívoco, tanto en lo concerniente al presente (estados de hecho) como en lo concerniente al futuro (propósitos del que escribe);

— (...) y que la firma que me pedía iba a ser tomada en serio». (p.27) 
Pero el desafío desconstructivo, más allá de las excrecencias frívolas (numerosísimas y desgraciadas), es básico en el verdadero debate de fondo que subsiste a comienzos del siglo XXI, el mismo que planteaba George Steiner ya en 1989 al inicio de su libro Presencias Reales (1989: 5):

\begin{abstract}
Continuamos hablando de que el sol 'sale' y 'se pone', como si el modelo copernicano del sistema solar no hubiese reemplazado definitivamente el sistema de Tolomeo. Nuestro vocabulario, nuestra gramática están poblados de metáforas vacías de sentido, de figuras desgastadas del lenguaje. Éstas se perpetúan con tenacidad en la carpintería, en los recovecos de nuestro hablar de todos los días. Se agitan como viejos harapos o como espectros que merodean por el desván. Por este motivo, los hombres y mujeres bienpensantes — particularmente en la realidad científica y tecnológica de Occidente- continúan refiriéndose a 'Dios'. Por este motivo el postulado de la existencia de Dios se mantiene en un tan gran número de giros y alusiones espontáneas. Ninguna reflexión, ninguna creencia plausible que garantice Su presencia. Ninguna prueba inteligible tampoco. Si Dios se aferra a nuestra cultura, a nuestro discurso rutinario, es bajo la forma de un fantasma gramatical, de un fósil anclado en la infancia del lenguaje racional: eso es lo que piensa Nietzsche y más de uno tras él». (Sin duda, Derrida).
\end{abstract}

Y continúa el agnóstico Steiner:

Este ensayo sostiene la tesis opuesta. Propone que toda comprensión coherente de la naturaleza y del funcionamiento del lenguaje, que todo examen coherente de la capacidad que tiene el lenguaje humano de comunicar sentido y sentimiento, están fundamentados, en último término, en la hipótesis de la presencia de Dios.

Con lo que llevo dicho, la Teoría debe afrontar la literatura y otros códigos o soportes alternativos en los que se manifiesta lo que hay detrás de esa noción que vinculamos al libro, debe, pues, abrirse a los Estudios Culturales (Aguiar e Silva, 2008), experimentando ampliaciones más o menos inéditas, sin por eso desconocer los límites que separan la literatura de lo que no tiene nada que ver.

En el enfoque postmoderno, Teoría (no por casualidad, de la Literatura se elide) ahora es - y cito a Culler (1997: 13-14):-1) especulación, 2) toda hipótesis no evidente, lo que incluye antropología, cinematografía, filosofía, filosofía de la ciencia, estudios de 'género', historia del arte, historia social, historia de las ideas lingüísticas, psicoanálisis, sociología, teoría política, historia de la sexualidad. Esta ampliación insólita, que incluye casi cualquier cosa, está en muchísimos sedicentes críticos postmodernos que, como sabemos, invocan, más o menos en vano, los nombres de unos Estudios Culturales, que partirían de Roland Barthes y toman como referencias, entre otras, las siguientes líneas y nombres propios: Materialismo Cultural (Raymond Williams), Pragmatismo (Rorty), Nuevo Historicismo (Veeser), Teoría postcolonial (Said), Multiculturalismo (Even-Zohar), Feminismo (Moi), Homosexualidad (Foucault), Teoría del género (Spivah) y las más concretas Maricoteoría y Teoría lésbica, que, según las 
declaraciones de David Foster (2005) a la revista digital Hipertexto, hacen furor hasta en lugares que yo no hubiera imaginado hasta hace poco.

Ejemplificaré los discursos - numerosísimos- que se derivan de estos planteamientos con la cita de un texto de un autor uruguayo, profesor de la Universidad de Ohio, que me entregaron para mi consideración con motivo de un curso que yo impartía en la Universidad de la República, de Uruguay. Se titula «¿Epistemología de la frontera o fronteras de la epistemología?»y, entre otras cosas, enseña la diferencia entre «frontera»y «rontería»:

Si la frontera es borde, la frontería es burdel, el mercado por antonomasia, un lugar de transacción y de transubstanciación, como sugiere Derrida (1987). De este modo, el ensamblaje frontera/frontería constituye un dispositivo de contención y un espacio de transgresión. La una es imposible sin la otra, como las caras de una moneda, impensables, incompletas por sí mismas, porque no hay transgresión posible sin un límite que transgredir y todo límite es fútil sin la transgresión que lo consagra. La frontera no existiría si no fuera transgredible, pero la transgresión se agota en sí misma, pues es pura densidad, intensidad, Jetztzeit. No empece el carácter tangible de la frontera, carece de realidad hasta el instante mismo de ser transgredida, pero el ethos transgresivo es gesto vano sin el obstáculo de la frontera. La transgresión, en última instancia, conjura y realiza los límites epistemológicos y ontológicos de la frontera; o dicho de otro modo, la transgresión constituye la frontera donde la frontera se extingue y se hace frontería, dando lugar a lo que Michel Foucault llama 'el pensamiento de afuera', 'una forma de pensamiento en la cual la interrogación de los límites reemplaza la búsqueda de totalidad y el accionar transgresivo reemplaza el movimiento de las contradicciones' (1977: 33-5). La frontera consumida en su transgresión, se consuma en frontería. (Trigo, 2005).

Silka Freire, la profesora de la Universidad de la República en Montevideo, que me facilitó el texto, me dijo también que el maestro en lo sucesivo se iba a dedicar a la Economía Política. Tenemos, pues, que agradecer que antes de marcharse a otros territorios disciplinarios, nos deje, además del libro Memorias migrantes, publicado en 2003 en Rosario, este otro testimonio de cómo se entiende la labor que hay que hacer en nuestros Departamentos de Filología..., cuando se ha perdido de vista la noción de literatura.

Sin entrar en la sustancia de lo que dice, en cuanto yo lo entienda, me parece que no cabe duda de que la trashumancia que implica esta labor conduce a un discurso oscuro para nuestros estudiantes y para el público en general. Beatriz Sarlo, en una conferencia de diciembre de 1984 se preguntaba ya: «¿a quién podemos interesar con nuestro discurso?» (...) (Sarlo, 1984).

Me parece que hemos caído en la «obscuritas» como consecuencia de haber perdido toda fijeza en el objeto que tratar; abrazados sin razón a la frase de Barthes de que «entre la jerga y la trivialidad, prefiero la jerga», 
como si fuera imposible atender a la realidad sin jerga (innecesaria) y sin trivialidad.

Claro que también puede ser un problema de siempre. En 2004 edité la Artis Rhetoricae. Compendosia coaptatio ex Aristotele, Cicerone et Quintiliano, publicada por Elio Antonio de Nebrija en 1515. El capítulo 26 («La elocución») está formado por textos espigados de Institutiones oratoriae de Quintiliano (capítulos VII y VIII). Sin embargo, la mención, ocasional en las Institutiones, de una ironía de Horacio (Epístola II), se restaura como cita en toda regla a favor de la claridad («perspicuitas») y en contra de la «obscuritas». Dice así:

\begin{abstract}
En cambio, la obscuridad se deriva de las palabras removidas de su uso, de las que, por ejemplo, dice Horacio: 'Y si ve algo que se mantiene aún en este mundo y no ha consumido el curso de sus días, siente fastidio y odio. En cambio, fanático de las cosas viejas, va repitiendo como dichas por las musas en el monte Albano las severas tablas que los decenviros sancionaron, los pactos concertados por los reyes con los Fabios o con los rígidos Sabinos, las crónicas pontificales, los añosos volúmenes de los vates (...). El que alaba el poema saliar de Numa, ignorándolo igual que yo, quiere parecer que él solo es el que sabe'. Así, pues, algunos afectan fama de erudición para que parezca que ellos solos son los que saben $^{5}$.
\end{abstract}

Citando por extenso la mención de Horacio, el lector del siglo XVI podía comprender la pedantería que perpetran los que se «especializan» en las «antigüedades» ignotas: el monte Albano, que albergaba el templo de Júpiter del Lazio; los decenviros, que codificaron en 451 a. C. las famosas Doce Tablas que sirvieron de fuente del derecho hasta el imperio; los Fabios, influyente gente patricia romana de entre el siglo II y el $\mathrm{V}$ antes de Cristo; el antiguo pueblo itálico de los Sabinos, enfrentado con los romanos por el famoso rapto de las sabinas; los textos litánicos de los primitivos sacerdotes salios en latín poco inteligible, etc. Quince siglos después, como digo, Nebrija no ha querido que pasara inadvertida la cita contra la pedantería, denunciada como contraria a la claridad que la Retórica patrocina, y, por eso, sobrepasa la alusión de Quintiliano, restaurándola íntegramente. Ciertamente la «obscuritas» que aquí se presenta es más bien la del ratón de biblioteca que la del especialista en jerga, pero el mal es el mismo: no saber de qué se habla.

Hay un aspecto en la mencionada conferencia de Sarlo, que yo no comparto. Ella extraña la falta de presencia social de nuestro mundo aca-

\footnotetext{
${ }^{5}$ At obscuritas fit in verbis ab uso remotis de quibus Horatius: «Et nisi quae terris semota suisque temporibus defuncta videt, fastidit et odit. Sic fautor veterum ut tabulas peccare vetantes, quas bis quinque viri sanxerunt foedera regum vel Fabiis vel cum rigidis aequata Sabinis ; Pontificum libros, annosa volumina vatum, dictitet Albano musas in monte locutas ; et paulo post, iam saliare Numae carmen qui laud et illud quod mecum ignorat, solo vult scire videri ». Hinc enim aliqui famam eruditionis affectant, ut soli scire videantur.
} 
démico en comparación con otros momentos de la historia de Argentina o con episodios de la academia británica. Parece que le molesta la vieja distinción del alemán entre Literaturwissenschaf, o sea, Ciencia de la Literatura, Teoría, Crítica de base teórica explícita, Crítica académica, y Literaturkitik, o sea, Crítica militante, Crítica periodística. Yo no me inquietaría por ello.

La verdad es que en los últimos treinta años esa frontera se ha cruzado en ambos sentidos. Cualquiera que siga, aunque sea de vez en cuando, el Times Literary Supplement, o el suplemento del Frankfurter Allgemeine o Le Figaro Littéraire o el suplemento de Le Monde o el de La Nación de Buenos Aires o los correspondientes suplementos de ABC, El Mundo, El País, La Razón o La Vanguardia, en España, puede observar una doble corriente: por una parte, cada vez son más los autores de la academia, que practican, incluso asiduamente, la crítica periodística; por otra, cada vez son más los periodistas que basan sus críticas en claves teóricas explícitas. Las fronteras se están desdibujando. Con todo, la influencia social directa de estas intervenciones es absolutamente irrelevante. Cuando en los años de la década de 1980, se daba el hecho insólito de que el conservador diario $\mathrm{ABC}$ de Madrid se veía los jueves masivamente en manos de los profesores progresistas de la Facultad de Letras de la Universidad Complutense de Madrid (y de otras universidades de España), porque incluía un prestigioso Suplemento Cultural, yo pensé que las ventas aumentaban ese día y pregunté. Pues bien, el hecho era estadísticamente irrelevante, cosa que no ocurría el lunes, día del Suplemento Deportivo.

Es cierto que hay que adaptar el registro al medio. Pero a mí me preocupa la obscuritas, sobre todo, porque supone una contradicción en los términos que el entrenador en comunicación transgreda las más elementales normas de la claridad (perspicuitas). Me parece que la mayoría de los tecnicismos son evitables, pero no me importan porque me alejen del lector extraacadémico. El lector implícito a quien va dirigida mi labor es el colega y el estudiante universitario, quienes, a través de la institución educativa, transmitirán esos saberes, actualizarán las orientaciones, mantendrán en estado de vigilia el patrimonio cultural, aunque no se citen los orígenes, aunque nadie sepa en la escuela secundaria y primaria de donde viene que la instrucción sea como es. Se trata de una hermosa e imprescindible tarea anónima. No es notoria, pero sí es fundamental. No se podrán medir los resultados, pero no se podrá desconocer que tales resultados existen.

Después de la época literaria, tiene que seguir siendo posible el entrenamiento en la comunicación, también y especialmente mediante la literatura: la indispensable tarea de enseñar a expresar lo que uno piensa y siente y a entender lo que nos dicen que piensan y sienten los demás. Tiene que ser posible el honor de la filología y, dentro de él, el discernir meridianamente entre las obras de Shakespeare, Cervantes y Dostoievski y las rece- 
tas de Arguiñano, la telenovela o la prensa chicha del Perú. Será necesario modular la teoría/crítica según el espacio, el tiempo y los intereses particulares, pero no es posible (plausible) abdicar.

\section{ACEPCIONES}

La página en línea de la $22^{\mathrm{a}}$ edición del DRAE ofrece las siguientes acepciones del término:

/literatura/

(Del latín litteratura)

1. f. Arte que emplea como medio de expresión una lengua

2. f. Conjunto de las producciones literarias de una nación, de una épo$\mathrm{ca}$, de un género. La literatura griega, La literatura del siglo XVI

3. f. Conjunto de obras que versan sobre un arte o una ciencia. Literatura médica. Literatura jurídica.

4. f. Conjunto de conocimientos sobre literatura. Sabe mucha literatura.

5. f. Tratado en que se exponen estos conocimientos.

6. f. desus. Teoría de la composiciones literarias.

Como se ve, la entrada académica actual recoge el uso etimológico de la expresión, el uso fundamental, que se refiere al registro artístico, y varias acepciones de éste, posibles por metonimia. Habrá que repensar la entrada. En este trabajo hemos ilustrado otra definición: «Comunicación artística por medio de las palabras del idioma, normalmente transmitidas mediante un libro impreso. Acepción lexicalizada en los siglos XIX y XX».

Esta definición del término (vigente) clarifica la correspondiente noción (vigente) de un lugar importantísimo que se da entre poesía (noción anterior, ampliamente recategorizada e integrada en literatura) y cíber, que es una de sus fronteras. Creemos haber mostrado que el conocimiento de los perfiles que lo delimitan (y sus consecuencias) son de gran importancia para el campo institucional de la cultura.

\section{REFERENCIAS BIBLIOGRÁFICAS}

AARSETH, A. (1997). Cybertext. Perspectivas on Ergodic Literature. Baltimore/Londres: John Hopkins University Press.

ADELL, Joan-Elias (2004). «Las palabras y las máquinas. Una aproximación a la creación poética digital». En: SÁNCHEZ MESA, D. (ed.), pp. 269-296.

AGUIAR E SILVA, Vítor M. (2008). «Genealogias, Lógicas e Horizontes dos Estudos Culturais». En: O Trabalho da Teoria. Actas do Colóquio em Homenagem a V. A. e S. R. M. Goulart, Fraga, M d. C., P. Meneses (eds.). Ponta Delgada: Universidade dos Açores, pp. 243-269. 
ALBALADEJO, T.; CHICO RICO, DEL RÍO, E. (eds.): (1998). Retórica, hoy. AlicanteMadrid: Universidad de Alicante-Verbum).

ANDRÉS, Juan (1784-1806). Origen, progreso y estado actual de toda literatura. Madrid: Verbum, 1998-2002, 6 vols.

ARISTÓTELES. Poética. García Yebra, V. (ed.). Madrid: Gredos, 1974.

BARTHES, R. (1970). S/Z. En : Oeuvres Complètes II. Paris: Seuil, 1994, pp. 557-757.

—. (1971). «De l'œuvre au texte». Euvres complètes II. Paris: Seuil, pp.1211-1217. [Revue d'Esthétique, 3er. trimestre].

BAUDRILLARD, Jean (1981): Simulacres et Simulation, Paris, Galilée.

BENJAMIN, Walter (1936). «La obra de arte en la época de su reproductibilidad técnica». En: Discursos interrumpidos I. Madrid: Taurus, 1973, 15-60.

BLOOM, H. (1994). El Canon occidental. La escuela y los libros de todas las épocas. Barcelona: Anagrama, 1995.

BOLTER, J. David (1991). Writing Space. The Computer, Hypertext and the History of Writing. Hillsdle and London: Lawrence Erlbaum.

CABO, Fernando (2001). «Poesía e hipertexto: la conciencia del límite». En: Abuin González, A. et alii (eds.). Homenaje a Benito Varela Jácome. Santiago de Compostela: Universidad, pp. 73-90.

CALVINO, Italo (1988). Seis lecciones para el próximo milenio. Madrid: Siruela, 1996.

CHICO RICO, F. (2007). «Literatura y teoría literaria en la era digital». Estudios literarios i. h. E. Torre. Sevilla: Universidad, pp. 787-800.

CORTI, Maria (1980). Principi della comunicazione letteraria. Milano: Bompiani.

CULLER, J. (1997). Breve Introducción a la teoría literaria. Barcelona: Crítica, 2000.

DERRIDA, Jacques (1987). De l'esprit. Heidegger et la question. Paris : Galilée.

ECO, U. (1988); El Péndulo de Foucault. Barcelona: Lumen, 1989.

-. (1990). I Limiti dell'interpretazione. Milano: Bampiani.

ESCARPIT, R. (1962). «La definición del término literatura». En: Hacia una sociología del hecho literario. Madrid: Edicusa, 1974, pp. 257-272.

FAUTH, Jürgen (2003). «Promesas y limitaciones de la narrativa hipertextual». En: Vega, María José (ed.), pp.120-128.

FOSTER, David W. (2005). «Conversaciones con...». Cortina, Guadalupe (A cargo de) Hipertexto. Revista digital. The University of Texas Pan American, verano de 2005, pp. 85-91.

FOUCAULT, M. (1997). «A Preface to Transgression». En: Language, Counter-Memory, Practice. Serlected Essays and Interviews. Ithaca : Cornell Univ. Press.

FUMAROLI, M. (1980). L’Âge de l'éloquence. Rhétorique et «res litteraria» de la Renaissance au seuil de l'époque classique. Génève: Droz.

GARCÍA BARRIENTOS, J.L. (2006): «La Teoría literaria en el fin de siglo: panorama desde España. Revista de Literatura, LXVIII/136, 405-445.

-.(2007). El Teatro del futuro. México D.F.: Paso de Gato (Cuadernos de Ensayo Teatral).

GARRIDO GALLARDO, M. A. (1976). Introducción a la Teoría de la literatura. Madrid: SGEL.

-. (1994). La Musa de la Retórica. Madrid: CSIC.

-. (2000): Nueva Introducción a la teoría de la literatura. Madrid: Síntesis, 2004, $3^{\mathrm{a}}$ ed. Corregida y aumentada.

—. (ed.) (2004): Retóricas españolas del siglo XVI escritas en Latín. Madrid: Fundación Hernando de Larramendi/CSIC.

—. (2006).«Fuerza y actualidad de los textos». En: El Impacto de la Biblia.. Caballero, J.L (ed.). Pamplona: Eunsa, 2006, pp. 15-38.

-. (2007): «El término literatura en un diccionario del siglo XXI». Boletín de la Academia Argentina de Letras LXXII, 289, pp. 5-12. 
GOUHIER, Henri (1943). La esencia del teatro. Madrid: Artola, 1954.

HERBRECHTER, S. and CALlUS, I. (eds.): Post-Theory, Critical Studies, 26, 2004.

KERNAN, Alvin (1990). The Death of Literature. New Haven: Yale University Press.

LÁZARO CARRETER, F. (1976). Estudios de lingüística. Barcelona: Crítica, 1980.

LYOTARD, J. F. (1979). La Condition postmoderne: rapport sur le savoir. Paris: Minuit.

MCLUHAN, Marshall (1964). Comprender los medios de comunicación. Las extensiones del ser humano. Barcelona: Paidós, 1996.

MOULTHROP, Stuart (2003). «El hipertexto y la política de la interpretación». En: Vega, María José (ed.), pp. 23-31.

NELSON, Th. H. (1987). Computer Lib/Dream Machines. Redmond,WA: Tempus Books.

NUNBERG, Geoffrey (comp.) (1996). El Futuro del libro. ¿Esto matará a eso? Con un epílogo de Umberto Eco. Barcelona: Paidós, 1998.

PONTÓN, Gonzalo (2003). «El hiperdrama. Alegoría escénica de la era digital». En: Vega María José (ed.), pp. 150-156.

QUINTILIANO, M. F. Institutionis Oratoriae Libri XII/Sobre la formación del orador: doce libros. Ortega Carmona, Alfonso (traducción y comentarios). Universidad Pontificia de Salamanca, 1997-2001, 5 vols.

REISS, T. (1992). The Meaning of Literature. Ithaca: Cornell Univ. Press.

RICOEUR, P. (1975). La Metáfora viva. Madrid: Ediciones Europa, 1980.

SÁNCHEZ MESA, D. (ed.) (2004). Literatura y cibercultura. Estudio. Compilación de textos. Bibliografía. Madrid: Arco/Libros.

SARLO, B. (1984). «La Crítica: entre la literatura y el público». Espacios, 1, 6-11.

SCHAEFFER, J.M. (1983). La Naissance de la littérature. La théorie esthétique du romantisme allemand. Paris: Presses de l'École Normale Supérieur.

SCHNELL, Ralf (ed.) (2009). Veränderungen des Literaturbetriebs, Zetschrift für Literaturwissenschaft un Linguistik, 154.

STÄEL, Mme. De [Anne-Louise-Germaine Necker] (1799). De la littérature considerée dans ses rapports avec les institutions sociales. Nouv. édition crit., Blaeschke, Axel (présentée et annot). Paris : Flammarion, 1998.

STEINER, G. (1989). Presencias reales, Madrid, Barcelona: Destino, 1991.

TRIGO, A. (2003). Memorias migrantes. Rosario: Beatriz Viterbo editora.

- (2005). ¿Epistemologías de la frontera o frontera de la epistemología ?. Original facilitado por Silka Freire. Cátedra «Dámaso Alonso» en Montevideo, (agosto de 2005).18 páginas.

VEGA, María José (ed.) (2003). Literatura hipertextual y teoría literaria. Madrid: Marenostrum.

WIENER, N. (1948). Cybernetics or Control and Communication in the Animal and the Machine. New York: Technology Press.

WOLFE, T. (1975). The New Journalism. London: Picador Pan Books.

Fecha de recepción: 14 de junio de 2008

Fecha de aceptación: 10 de marzo de 2009 